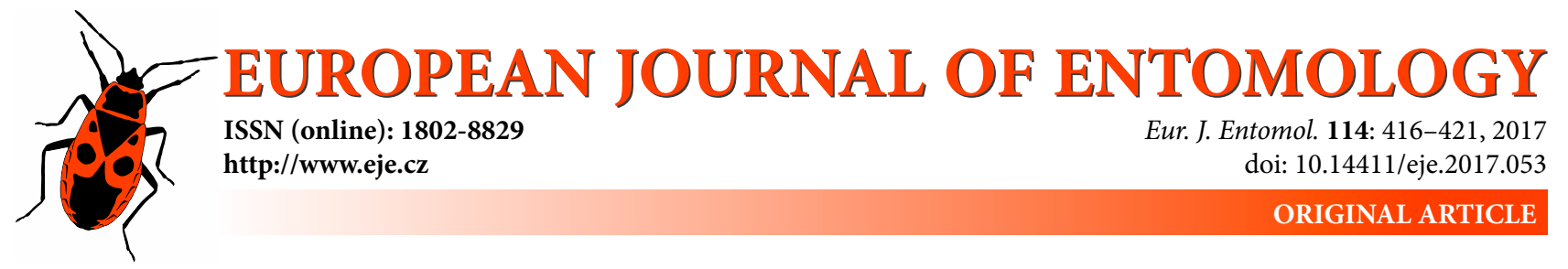

\title{
Inheritance of diapause regulation in the multicoloured Asian ladybird Harmonia axyridis (Coleoptera: Coccinellidae)
}

\author{
Sergey Ya. REZNIK ${ }^{1,2}$, Antonina A. OVChINNIKOVA ${ }^{1}$, Andrey N. OVCHINNIKOV ${ }^{1}$, LaRisa V. BARABANOVA \\ and Natalia A. BELYAKOVA 4 \\ ${ }^{1}$ Zoological Institute, Russian Academy of Sciences, 199034 St. Petersburg, Russia; e-mails: reznik1952@mail.ru, \\ antoninaovch@gmail.com, anovchi@gmail.com \\ 2 St. Petersburg Scientific Center, Russian Academy of Sciences, 199034 St. Petersburg, Russia \\ ${ }^{3}$ St. Petersburg State University, 199034 St. Petersburg, Russia; e-mail: Ibarabanova@mail.ru \\ ${ }^{4}$ All-Russian Institute of Plant Protection, Russian Academy of Sciences, Pushkin, 196608, St. Petersburg, Russia; \\ e-mail: belyakovana@yandex.ru
}

Key words. Coleoptera, Coccinellidae, Harmonia axyridis, photoperiod, diapause, variability, genetics, inheritance

\begin{abstract}
It is known that females from native populations of the multicoloured Asian ladybird, Harmonia axyridis, have a strong photoperiodic response (enter reproductive diapause under short photoperiods), whereas the proportion of diapausing females from invasive populations is less dependent on day length. The aim of the present study was to determine the mode of inheritance of these differences. The experiments were conducted with two laboratory populations of $H$. axyridis, the High Diapause (HD) population originated from Irkutsk (Southern Siberia, ca $52.3^{\circ} \mathrm{N}, 104.3^{\circ} \mathrm{E}$ ) and the Low Diapause (LD) population originated from Sochi (North Caucasus, ca $43.6^{\circ} \mathrm{N}, 39.6^{\circ} \mathrm{E}$ ). Reciprocal first generation hybrids and reciprocal backcrosses were investigated. Under a strong diapause-inducing photoperiod $(12 \mathrm{~h}$ ) $100 \%$ of the females from the HD population and about $70 \%$ of those from the LD population entered diapause. First generation hybrids, as well as their backcrosses with individuals from the HD population, showed almost $100 \%$ diapause. Among the backcrosses with the LD population the percentage of diapausing females was widely variable (70-100\%) but close to the average between the two populations. The comparison of reciprocal crosses did not reveal any significant difference. We conclude that photoperiodic induction of diapause in the populations of $H$. axyridis studied is most probably determined by several genes (although one of them evidently plays a leading role with diapause being dominant over non-diapause) and that male and female genotypes are equally important in the determination of female reproductive diapause.
\end{abstract}

\section{INTRODUCTION}

Diapause is an important component of insect life history crucial for surviving harsh seasonal conditions and for synchronizing reproduction and development with favorable environments (Tauber et al., 1986). It is well established that photoperiodic, thermal, trophic and other diapauseregulating responses are well adapted to local climate and therefore may differ not only between species but also between geographically distant populations of the same species (Denlinger, 2002; Saunders et al., 2002; Saunders, 2010; Goto \& Numata, 2014). This intra-specific variability has been thoroughly investigated in several model insects (Lumme et al., 1975; Henrich \& Denlinger, 1983; Kim et al., 1995; McWatters \& Saunders, 1997; Doležel et al., 2005; Williams et al., 2006; Goto, 2009; Han \& Denlinger, 2009) and in some other, mostly economically important, Coleoptera (Sakakibara \& Kawakami, 1992; Kuang et al., 2011; Chen et al., 2012, 2014; French et al., 2014; Lehmann et al., 2016; Tanaka \& Murata, 2016), Le- pidoptera (Ikten et al., 2011; Söderlind \& Nylin, 2011; Xia et al., 2012; Huang et al., 2013; Fu et al., 2015; Xiao et al., 2015; Pruisscher et al., 2017), Diptera (Meuti et al., 2015), Hymenoptera (Paolucci et al., 2016) and spider mites (Ignatowicz \& Helle, 1986; Takafuji \& Goka, 1999; Suwa \& Gotoh, 2006; Kawakami et al., 2010). These studies reveal that the genetic basis and mode of inheritance of diapauseregulating responses differ markedly among insects. Thus, each specific case of inter-population variability deserves to be investigated because the results of these studies can be used for a meta-analysis and further synthesis. In particular, as regards Coccinellidae, although it is demonstrated that the tendency for the adults of Coccinella septempunctata L. to enter diapause can be changed by artificial selection (Hodek \& Cerkasov, 1961) the genetic bases of these changes have not been investigated. Therefore, the inheritance of diapause-controlling reactions is considered an important area of investigation for furthering the under- 
standing of the biology of ladybirds (Hodek, 2012; Sloggett \& Honěk, 2012).

Genetic aspects of the regulation of diapause are especially important when considering widely distributed and rapidly spreading invasive species that have to permanently adapt to different climatic conditions (Handley et al., 2011; Sloggett, 2012). One of them is the object of our study, the multicoloured Asian (or harlequin) ladybird, Harmonia axyridis (Pallas) originating from South-Eastern Asia, that has recently colonized numerous countries in America, Africa and Europe (Lombaert et al., 2010, Roy et al., 2016). Native and invasive populations of $H$. axyridis differ in various biological features (Sloggett, 2012). In particular, the females of Siberian and Korean native populations have a clear photoperiodic response (under short photoperiods, females enter reproductive diapause), whereas the percentage of females entering diapause in European and Caucasian invasive populations is less dependent on day length (Reznik et al., 2015a). These results indicate that there are genetic differences in the photoperiodic responses of individuals in native and invasive populations of $H$. $a x y$ ridis the mode of inheritance of which is unknown.

Therefore, in the present work, we studied the inheritance of the diapause-controlling photoperiodic responses in $H$. axyridis. The results of this study are not only of theoretical but also of practical importance. Several authors note that hybridization between individuals from different native, invasive and mass-reared populations of $H$. axyridis has had an effect on the worldwide spread of this species (Facon et al., 2008, 2011; Lombaert et al., 2010; Handley et al., 2011; Turgeon et al., 2011; Seko et al., 2012). Thus, the mode of inheritance of diapause regulation could be a significant factor in the further spread of the multicoulored Asian ladybird. On the other hand, the ability to avoid diapause and reproduce under short day conditions can be important for the mass rearing of $H$. axyridis and their use as biocontrol agents in greenhouses.

\section{MATERIAL AND METHODS}

The study was conducted with two laboratory populations of $H$. axyridis. The High Diapause (HD) native population originated from 420 adults collected 31.vii.2015 in the environs of Irkutsk, Southern Siberia, Russia (ca $52.3^{\circ} \mathrm{N}, 104.3^{\circ} \mathrm{E}$ ). The Low Diapause (LD) invasive population originated from 670 adults collected 18.-28.vii.2015 in Sochi, Russian North Caucasus (ca $43.6^{\circ} \mathrm{N}, 39.6^{\circ} \mathrm{E}$ ). It is known that Siberia is in the natural distribution range of $H$. axyridis, whereas in the North Caucasus the first population of this species was found only several years ago (Belyakova \& Reznik, 2013; Ukrainsky \& Orlova-Bienkowskaja, 2014; Orlova-Bienkowskaja et al., 2015; Roy et al., 2016).

As noted above, our earlier study indicates that under short photoperiods (day length of $10-14 \mathrm{~h}$ ) females from the native HD population entered reproductive diapause, whereas the percentage of females from the invasive LD population that entered diapause was lower and almost independent of photoperiodic conditions. The results indicate that photoperiodic responses of these populations are more strongly influenced by invasion history than latitudinal differences, because both the Siberian (Irkutsk, $52.3^{\circ} \mathrm{N}$ ) and the Korean (Daegu, $35.9^{\circ} \mathrm{N}$ ) native populations of $H$. axyridis show a clear photoperiodic response, whereas the photoperiodic response of invasive populations from Europe (Pardubice, $50.0^{\circ} \mathrm{N}$ ) and the Caucasus (Sochi, $43.6^{\circ} \mathrm{N}$ ) is weak (Reznik et al., 2015a).

We studied reciprocal first generation $\left(\mathrm{F}_{1}\right)$ hybrids and reciprocal backcrosses between $F_{1}$ and individuals from parental populations (Table 1). The hybridization experiments were performed in 2016-2017. Previously, both populations were reared under standard conditions: temperature of $20^{\circ} \mathrm{C}$, day length of $18 \mathrm{~h}$, relative air humidity of $75-85 \%$ and fed on the green peach aphid, Myzus persicae (Sulz.). In the experiments, larvae, pupae and adults of the parental individuals were reared under the same conditions. Their progeny (which were tested for the photoperiodic induction of diapause) were kept under a short $(12 \mathrm{~h})$ photoperiod, other conditions were the same. This day length was selected in order to estimate the general ability to enter diapause (rather than to compare photoperiodic thresholds) because, based on the results of our earlier study (Reznik et al., 2015a), a $12 \mathrm{~h}$ long day is perceived as "short" (diapause-inducing) by individuals from both native and invasive populations. Larvae of the parental and progeny generations were reared individually in plastic Petri dishes $(60 \times 12 \mathrm{~mm})$ and fed on green peach aphids offered on seedlings of broad bean, Vicia faba L. Fresh food was provided to larvae and adults as needed (daily or every other day). Both parental individuals and their progeny were sexed immediately after emergence from pupae and were then kept in pairs on the same diet in Petri dishes of the same size. Parental individuals were kept alive until the required number of eggs was laid. Progeny adults were dissected 20 days after emergence to check for diapause; this period of time was selected based on the results of our earlier experiments (Reznik \& Vaghina, 2011; Reznik et al., 2015a). It is well known that the most important sign of reproductive diapause in insects and, particularly, in ladybirds is inactive poorly developed ovaries (Tauber et al., 1986; Hodek, 2012). Therefore, during dissection of females, the state of the ovaries was described as "poorly developed" (follicles are not visible or their width does not exceed the width of a germarium) or "well developed" (follicles are well visible, non transparent). Then the percentage of diapausing (with poorly developed ovaries) females was calculated for the progeny of each parental pair. In addition, the state of the fat body was also recorded for each female as "poorly developed" (thin lobes interspersed around the internal organs) or "well de-

Table 1. The percentage of diapausing females in progeny of different crosses between individuals from High Diapause (HD) and Low Diapause (LD) populations of Harmonia axyridis (in the designation of crosses, the female is listed first). This experiment was conducted at $20^{\circ} \mathrm{C}$ and $12 \mathrm{~L}: 12 \mathrm{D}$. The percentage of diapausing females in progeny (median and quartiles) is shown in the right column, values followed by the same letter are not significantly different ( $p>0.05$ using the Tukey's HSD test of ranked data).

\begin{tabular}{|c|c|c|c|}
\hline \multirow[b]{2}{*}{ Crosses } & \multicolumn{2}{|c|}{ Sample size } & \multirow[b]{2}{*}{$\begin{array}{l}\text { Diapausing females } \\
\text { in progeny }(\%)\end{array}$} \\
\hline & $\begin{array}{l}\text { Parental } \\
\text { pairs }\end{array}$ & $\begin{array}{c}\text { Dissected } \\
\text { progeny females }\end{array}$ & \\
\hline $\mathrm{HD} \times \mathrm{HD}$ & 10 & 96 & $100(100-100) \mathrm{c}$ \\
\hline LD $\times$ LD & 10 & 113 & $73(55-90) a$ \\
\hline$H D \times L D$ & 10 & 109 & $100(100-100) b c$ \\
\hline LD $\times H D$ & 10 & 116 & $100(100-100) b c$ \\
\hline$(\mathrm{HD} \times \mathrm{LD}) \times \mathrm{HD}$ & 9 & 73 & $100(97-100) \mathrm{bc}$ \\
\hline$H D \times(H D \times L D)$ & 8 & 81 & $100(100-100) b c$ \\
\hline$(\mathrm{LD} \times \mathrm{HD}) \times \mathrm{HD}$ & 7 & 53 & $100(100-100) b c$ \\
\hline$H D \times(L D \times H D)$ & 6 & 43 & $100(100-100) b c$ \\
\hline$(\mathrm{HD} \times \mathrm{LD}) \times \mathrm{LD}$ & 9 & 102 & $90(70-100) a b$ \\
\hline $\mathrm{LD} \times(\mathrm{HD} \times \mathrm{LD})$ & 10 & 97 & $85(75-100) a$ \\
\hline$(\mathrm{LD} \times \mathrm{HD}) \times \mathrm{LD}$ & 9 & 100 & $100(92-100) a b$ \\
\hline $\mathrm{LD} \times(\mathrm{LD} \times \mathrm{HD})$ & 8 & 85 & $100(88-100) a b$ \\
\hline
\end{tabular}


veloped" (well-formed globules and interconnected lobes, the internal organs completely or nearly completely hidden). In total, the experiment included 106 parental pairs and 1068 dissected female progeny (Table 1).

To reveal within-cross heterogeneity (to compare the numbers of diapausing and non-diapausing females in the progeny of different parental pairs within the same type of cross), the FisherFreeman-Halton exact test calculated using StatXact 10 was used. To compare different crosses, the percentages of diapausing females in the progeny of each parental pair were ranked and then Tukey's HSD test was used. To estimate the correlation between development of ovaries and fat body in individual females, Pearson chi-square test was used (these calculations were made using SYSTAT 10.2). In the text, table, and figure, untransformed results (percentages) are given.

\section{RESULTS}

As indicated in Table 1, all females in the progeny of individuals from HD populations (HD $\times$ HD crosses) have poorly developed ovaries (i.e. were in diapause), whereas in the progeny of LD $\times$ LD pairs only about $70 \%$ of females entered diapause despite the strong diapause-inducing regime used in this experiment. Almost all of the progeny of first generation hybrids, $\mathrm{HD} \times \mathrm{LD}$ and $\mathrm{LD} \times \mathrm{HD}$ (here and after, in designated crosses, the female is listed first) entered diapause (Table 1, Fig. 1C) indicating that diapause is a completely (or almost completely) dominant character. The percentages of diapausing females in the progeny of backcrosses of $F_{1}$ hybrids with individuals from the HD population were not significantly different from that in the progeny of HD $\times$ HD crosses (Table 1 ), which also indicates the dominance of diapause.

Backcrosses of $F_{1}$ hybrids with individuals from the LD population, in contrast, significantly differed from HD $\times$ HD crosses (Table 1). Comparison of the distribution graphs showed that about half of the parental pairs of backcrosses with the LD populations (Fig. 1E) produced only diapausing progeny, like the HD $\times$ HD crosses (Fig. $1 \mathrm{~A})$, whereas in the other half of the pairs, the percentage of diapausing progeny varied similarly to that recorded for the $\mathrm{LD} \times \mathrm{LD}$ crosses (Fig. 1B). In combination, these data argue for monogenic inheritance with dominance of diapause induction. On the other hand, the percentage of diapausing progeny of different pairs of $L D \times L D$ crosses was very variable (Fig. 1B). Considering the standard experimental conditions, this variation indicates that some other genes had an effect and the LD population was relatively highly genetically heterogeneous.

The comparison of reciprocal crosses did not reveal any significant difference (Table 1). In other words, male and female genotypes were equally important for the induction of reproductive diapause in females of the multicoloured Asian ladybird.

Finally, it should be noted that $98 \%$ of females with poorly developed ovaries $(n=988)$ and only $31 \%$ of those with well developed ovaries $(n=80)$ had well developed fat bodies $\left(\chi^{2}=504.6, p<0.001\right)$.
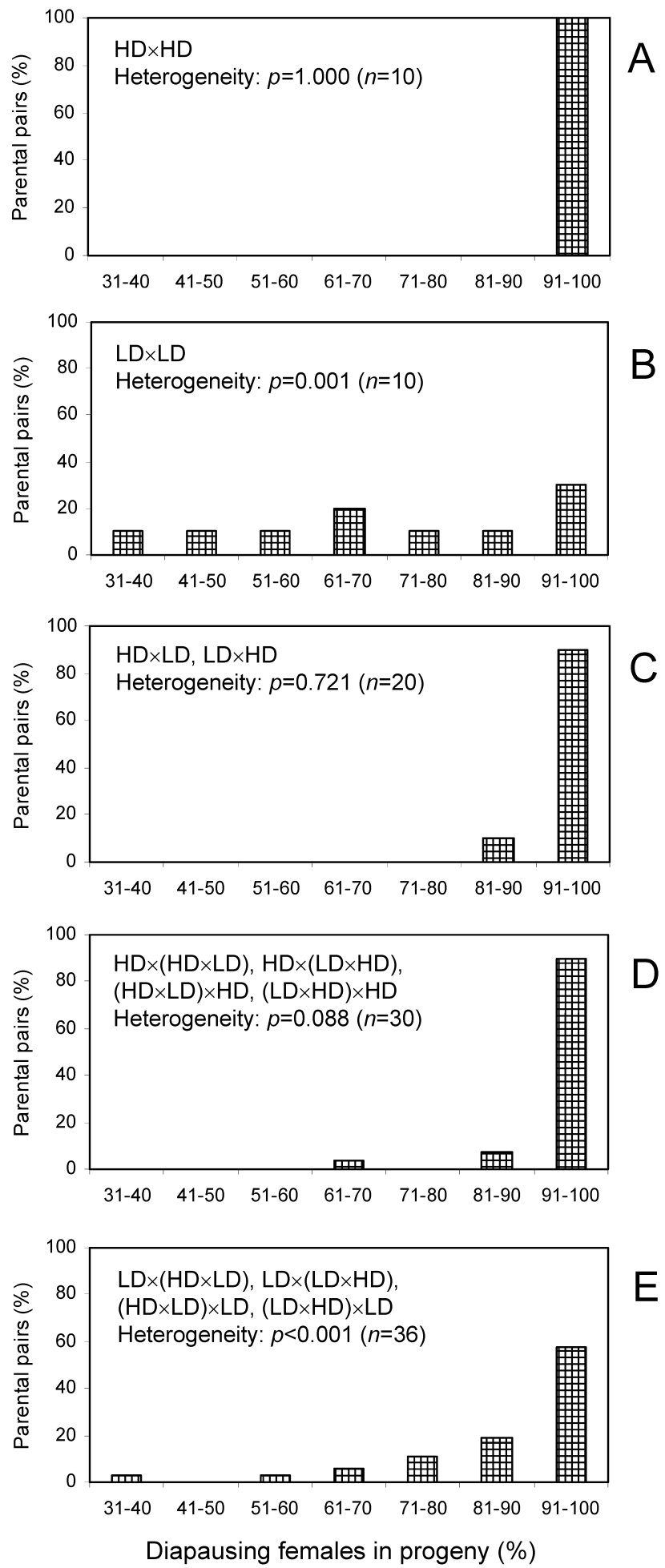

Fig. 1. Percentages of parental pairs with different percentages of diapausing females in the progeny of different types of crosses between individuals from Low Diapause (LD) and High Diapause (HD) populations of Harmonia axyridis (in the designation of crosses, the female is listed first). Statistical significance of heterogeneity of parental pairs within the same type of crosses was calculated using the Fisher-Freeman-Halton exact test.

\section{DISCUSSION}

As expected (Hodek, 2012), practically all of the females with poorly developed ovaries had a well developed fat 
body suggesting that they had entered reproductive diapause (which ensures successful overwintering) rather than merely delaying maturation. Most of the reproductively active females, on the contrary, had poorly developed fat bodies. Some individuals, however, at the time of dissection had both a well developed fat body and well visible follicles in their ovaries indicating, most probably, they had just matured after a short-term delay. Similar results are recorded in earlier studies (Reznik \& Vaghina, 2006; Reznik et al., 2015b).

Different insects show various modes of inheritance of diapause regulation. Similar to that recorded in this study, diapause is dominant in the linden bug, Pyrrhocoris apterus L. (Dolezel et al., 2005), Drosophila littoralis Meigen (Lumme et al., 1975) and two Tetranychus species (Ignatowicz \& Helle, 1986; Takafuji \& Goka, 1999). In contrast, in certain other insects and mites diapause is a recessive character (Sakakibara \& Kawakami, 1992; Suwa \& Gotoh, 2006; Han \& Denlinger, 2009; Chen et al., 2012; French et al., 2014). In the face fly, Musca autumnalis De Geer (Kim et al., 1995) and flesh fly Sarcophaga similis Meade (Goto, 2009) diapause is only partially dominant. Finally, in some of the insects studied, the percentage of diapausing individuals in $\mathrm{F}_{1}$ hybrids is close to the average between those of their parents (Kuang et al., 2011; Söderlind \& Nylin, 2011; Chen et al., 2014; Paolucci et al., 2016). The degree of dominance of diapause can differ markedly even in closely related species. For example, both Tetranychus kanzawai Kishida and T. pueraricola Ehara et Gotoh show simple Mendelian inheritance of diapause, but in the first species it is dominant (Takafuji \& Goka, 1999), whereas in the second species it is a recessive character (Suwa \& Gotoh, 2006). Moreover, crosses between individuals from different natural populations of Tetranychus urticae Koch show that diapause is a recessive character, whereas the experiments on the artificially selected non-diapause strain of the same species reveal the dominance of diapause (Kawakami et al., 2010). It should also be noted that the results of genetic analysis can depend on photothermal regimes and, possibly, on other details of experimental methods. For example, the first studies conducted with the Asian corn borer, Ostrinia furnacalis Guenée indicate that diapause is incompletely dominant over non-diapause (Xia et al., 2012; Huang et al., 2013), but Fu et al. (2015) state that diapause is completely dominant and, finally, the experiments conducted by Xiao et al. (2015) show incomplete dominance of either diapause or non-diapause depending on the photoperiod.

Our experiments indicate that the induction of diapause in $H$. axyridis depends on several genes but one of them evidently plays a leading role. In many other insects of different orders diapause induction is under polygenic control (Kim et al., 1995; Söderlind \& Nylin, 2011; Lehmann et al., 2016; Tanaka \& Murata, 2016), although monogenic Mendelian inheritance is recorded in Pyrrhocoris apterus (Dolezel et al., 2005), Drosophila littoralis (Lumme et al., 1975), some other Diptera (Han \& Denlinger, 2009) and several spider mites (Ignatowicz \& Helle, 1986; Takafuji \& Goka, 1999; Suwa \& Gotoh, 2006; Kawakami et al., 2010).

We demonstrated that male and female genotypes have equal effects on the induction of reproductive diapause in $H$. axyridis. Earlier studies indicate that the male plays a more important role in the determination of diapause in its progeny, for example, in several species of Lepidoptera (Ikten et al., 2011; Chen et al., 2012; Xia et al., 2012; Huang et al., 2013; Fu et al., 2015; Xiao et al., 2015; Pruisscher et al., 2017). In some other insects in other orders, however, females have the same (Paolucci et al., 2016) or an even stronger (Kuang et al., 2011; Chen et al., 2014; French et al., 2014) influence than males on diapause in their progeny. In some cases, the relative importance of male and female parents depends on the parameter of diapause studied. For example, in the blow fly, Calliphora vicina $\mathrm{R}$.-D., the percentage of progeny entering diapause is mainly determined by the maternal genotype, whereas the duration of diapause depends on that of both parents (McWatters \& Saunders, 1997). In the Asian corn borer Ostrinia furnacalis the duration of diapause is also equally influenced by each parent, but the induction of diapause is mainly determined by paternal genes (Xiao et al., 2015). It is also important to remember that the results of reciprocal crosses can be determined not only by the relative importance of maternal and paternal genotypes but also by epigenetic maternal effects (Denlinger, 2002; Saunders et al., 2002; Saunders, 2010; Meuti et al., 2015).

Our study revealed a high level of heterogeneity in the invasive population. High genetic diversity is commonly considered an important prerequisite for a biological invasion by the multicoloured Asian ladybird (Facon et al., 2008, 2011; Lombaert et al., 2010; Turgeon et al., 2011; Seko et al., 2012). Moreover, meta-analysis of the data on various invaders suggests that high levels of genotypic diversity in founder groups increase establishment success (Forsman, 2014), although there are exceptions to this rule (Handley et al., 2011). The European invasive population of $H$. axyridis quite recently invaded Russia and continues to disperse north-eastwards (Belyakova \& Reznik, 2013; Ukrainsky \& Orlova-Bienkowskaja, 2014; Roy et al., 2016). Our experiments, in particular, show that some families of the Caucasian population of $H$. axyridis are more prone to diapause and it can be expected that their progeny have more chances of spreading further north to European Russia. In this context, it should be noted that a similar study conducted under the same laboratory conditions with insects collected in the Sochi region 3 years earlier (Reznik et al., 2015a) report a much lower incidence of diapause. This difference suggests natural selection towards a high propensity to enter diapause. As regards further spread, it is known that while the European invasive population of $H$. axyridis continues to move eastwards, the native Siberian population is gradually dispersing westwards (OrlovaBienkowskaja et al., 2015). Thus, it is conceivable that the two populations will meet. The outcome of this meeting, in particular, depends on the mode of inheritance of diapause regulation: both first generation hybrids and backcrosses 
with the native population will show a strong photoperiodic response ensuring timely induction of diapause, which is crucial for survival during severe continental winters.

Summarizing, we conclude that photoperiodic induction of diapause in the populations of $H$. axyridis studied is most probably determined by several genes (although one of them evidently plays a leading role with diapause being dominant over non-diapause) and that male and female genotypes are equally important in the determination of female reproductive diapause. Under natural conditions, this mode of inheritance would benefit the survival of hybrids between the native and invasive populations. As regards the mass rearing of non-diapausing strains, any occasional contamination could cause the induction of diapause in a significant fraction of the progeny.

ACKNOWLEDGEMENTS. We are grateful to L.S. Ramenskaya and O.S. Bezman-Moseyko (Zoological Institute RAS) for their assistance in conducting experiments. We greatly appreciate the useful comments on our manuscript of four anonymous reviewers. This study was partly supported by the Russian Foundation for Basic Research (grant 15-29-02526 ofi m).

\section{REFERENCES}

Belyakova N.A. \& ReZniK S.YA. 2013: First record of the harlequin ladybird, Harmonia axyridis (Coleoptera: Coccinellidae) in the Caucasus. - Eur. J. Entomol. 110: 699-702.

Chen C., XIa Q.W., Chen Y.S., Xiao H.J. \& Xue F.S. 2012: Inheritance of photoperiodic control of pupal diapause in the cotton bollworm, Helicoverpa armigera (Hübner). - J. Insect Physiol. 58: 1582-1588.

Chen C., Xiao L., He H.M., Xu J. \& Xue F.S. 2014: A genetic analysis of diapause in crosses of a southern and a northern strain of the cabbage beetle Colaphellus bowringi (Coleoptera: Chrysomelidae). - Bull. Entomol. Res. 104: 586-591.

DenLinger D.L. 2002: Regulation of diapause. - Annu. Rev. Entomol. 47: 93-122.

Doležel D., VanĚČKová H., ŠAuman I. \& Hodková M. 2005: Is period gene causally involved in the photoperiodic regulation of reproductive diapause in the linden bug, Pyrrhocoris apterus? - J. Insect Physiol. 51: 655-659.

Facon B, Pointier J.P., Jarne P., Sarda V. \& David P. 2008: High genetic variance in life-history strategies within invasive populations by way of multiple introductions. - Curr. Biol. 18: 363-367.

Facon B., Crespin L., Loiseau A., Lombaert E., Magro A. \& Estoup A. 2011: Can things get worse when an invasive species hybridizes? The harlequin ladybird Harmonia axyridis in France as a case study. - Evol. Appl. 4: 71-88.

ForSMAN A. 2014: Effects of genotypic and phenotypic variation on establishment are important for conservation, invasion, and infection biology. - Proc. Natn. Acad. Sci. USA 111: 302-307.

French B.W., CoAtes B.S. \& SAppington T.W. 2014: Inheritance of an extended diapause trait in the Northern corn rootworm, Diabrotica barberi (Coleoptera: Chrysomelidae). - J. Appl. Entomol. 138: 213-221.

Fu S., Chen C., Xiao L., He H. \& Xue F. 2015: Inheritance of diapause in crosses between the northernmost and the southernmost strains of the Asian corn borer Ostrinia furnacalis. PLoS ONE 10(2): e 0118186, 16 pp.

Gото S.G. 2009: Genetic analysis of diapause capability and association between larval and pupal photoperiodic responses in the flesh fly Sarcophaga similis. - Physiol. Entomol. 34: $46-51$.

Goto S.G. \& Numata H. 2014: Insect photoperiodism. In Hoffmann K.H. (ed.): Insect Molecular Biology and Ecology. CRC Press, Boca Raton, FL, pp. 217-244.

Han B. \& Denlinger D.L. 2009: Mendelian inheritance of pupal diapause in the flesh fly, Sarcophaga bullata. - J. Hered. 100: 251-255.

Handley L.J.L., Estoup A., Evans D.M., Thomas C.E., Lombaert E., Facon B., Aebi A. \& Roy H.E. 2011: Ecological genetics of invasive alien species. - BioControl 56: 409-428.

Henrich V.C. \& Denlinger D.L. 1983: Genetic differences in pupal diapause incidence between two selected strains of the flesh fly. - J. Hered. 74: 371-374.

HodeK I. 2012: Diapause / Dormancy. In Hodek I., van Emden H.F. \& Honěk A. (eds): Ecology and Behaviour of the Ladybird Beetles (Coccinellidae). Wiley-Blackwell, Chichester, pp. 275-342.

Hodek I. \& Cerkasov J. 1961: Prevention and artificial induction of the imaginal diapause in Coccinella septempunctata L. (Col.: Coccinellidae). — Entomol. Exp. Appl. 4: 179-190.

Huang L.L., Chen C., Xiao L., Xia Q.W., Hu L.T. \& Xue F. 2013: Geographical variation and inheritance of the photoperiodic response controlling larval diapause in two distinct voltine ecotypes of the Asian corn borer Ostrinia furnacalis. - Physiol. Entomol. 38: 126-132.

IgNatowicz S. \& Helle W. 1986: Genetics of diapause supression in the two-spotted spider mite, Tetranychus urticae Koch. Exp. Appl. Acarol. 2: 161-172.

Ikten C., Skoda S.R., Hunt T.E., Molina-Ochoa J. \& Foster J.E. 2011: Genetic variation and inheritance of diapause induction in two distinct voltine ecotypes of Ostrinia nubilalis (Lepidoptera: Crambidae). - Ann. Entomol. Soc. Am. 104: 567-575.

Kawakami Y., Numata H., Ito K. \& Goto S.G. 2010: Dominant and recessive inheritance patterns of diapause in the two-spotted spider mite Tetranychus urticae. - J. Hered. 101: 20-25.

Kim Y., KRafsur E.S., Bailey T.B. \& ZhaO S. 1995: Mode of inheritance of face fly diapause and its correlation with other developmental traits. - Ecol. Entomol. 20: 359-366.

KuANG X.J., Xu J., XIA Q.W., He H.M. \& Xue F.S. 2011: Inheritance of the photoperiodic response controlling imaginal summer diapause in the cabbage beetle, Colaphellus bowringi. J. Insect Physiol. 57: 614-619.

Lehmann P., Margus A. \& Lindström L. 2016: Inheritance patterns of photoperiodic diapause induction in Leptinotarsa decemlineata. - Physiol. Entomol. 41: 218-223.

Lombaert E., Guillemaud T., Cornuet J.M., Malausa T., Facon B. \& Estoup A. 2010: Bridgehead effect in the worldwide invasion of the biocontrol harlequin ladybird. - PLOS ONE 5(3): e9743, 7 pp.

Lumme J., LakovaAra S., OiKarinen A. \& LoKki J. 1975: Genetics of the photoperiodic diapause in Drosophila littoralis. - Hereditas 79: 143-148.

MCWATTERS H.G. \& SAUNDERS D.S. 1997: Inheritance of the photoperiodic response controlling larval diapause in the blow fly, Calliphora vicina. - J. Insect Physiol. 43: 709-717.

Meuti M.E., Short C.A. \& Dentinger D.L. 2015: Mom matters: Diapause characteristics of Culex pipiens - Culex quinquefasciatus (Diptera: Culicidae) hybrid mosquitoes. - J. Med. Entomol. 52: 131-137.

Orlova-Bienkowskaja M.J., Ukrainsky A.S. \& Brown P.M. 2015: Harmonia axyridis (Coleoptera: Coccinellidae) in Asia: a re-examination of the native range and invasion to southeastern Kazakhstan and Kyrgyzstan. — Biol. Invas. 17: 1941-1948. 
Paolucci S., Salis L., Vermeulen C.J., Beukeboom L.W. \& Zande L. 2016: QTL analysis of the photoperiodic response and clinal distribution of period alleles in Nasonia vitripennis. - Mol. Ecol. 25: 4805-4817.

Pruisscher P., Larsdotter-Mellström H., Stefanescu C., Nylin S., Wheat C.W. \& Gotthard K. 2017: Sex-linked inheritance of diapause induction in the butterfly Pieris napi. - Physiol. Entomol. 42: 257-265.

ReZNIK S.YA. \& VAGHINA N.P. 2006: Dynamics of fat content during induction and termination of "trophic diapause" in Harmonia sedecimnotata Fabr. females (Coleoptera, Coccinellidae). - Entomol. Rev. 86: 125-132.

Reznik S.YA. \& VAghina N.P. 2011: Photoperiodic control of development and reproduction in Harmonia axyridis (Coleoptera: Coccinellidae). - Eur. J. Entomol. 108: 385-390.

Reznik S.Ya., Dolgovskaya M.Yu., Ovchinnikov A.N. \& BelyaKOVA N.A. 2015a: Weak photoperiodic response facilitates the biological invasion of the harlequin ladybird Harmonia axyridis (Pallas) (Coleoptera: Coccinellidae). - J. Appl. Entomol. 139: 241-249.

Reznik S.Ya., Dolgovskaya M.Yu. \& Ovchinnikov A.N. 2015b: Effect of photoperiod on adult size and weight in Harmonia axyridis (Coleoptera: Coccinellidae). - Eur. J. Entomol. 112: 642-647.

Roy H.E., Brown P.M., Adriaens T., Berkvens N., Borges I., Clusella-Trullas S., Comont R.F., De Clerce P., Eschen R., Estoup A. ET AL. 2016: The harlequin ladybird, Harmonia axyridis: global perspectives on invasion history and ecology. Biol. Invas. 18: 997-1044.

SAKAKIBARA M. \& KaWAKAMI K. 1992: Larval diapause inheritance mode in two ecotypes of the yellow-spotted longicorn beetle, Psacothea hilaris (Pascoe) (Coleoptera: Cerambycidae). - Appl. Entomol. Zool. 27: 47-56.

SAUNDERS D.S. 2010: Photoperiodism in insects: migration and diapause responses. In Nelson R.J., Denlinger D.L. \& Somers D.E. (eds): Photoperiodism: The Biological Calendar. Oxford University Press Scholarship Online, USA, pp. 218-257.

Saunders D.S., Steel C.G.H., Vafopoulou X. \& Lewis R.D. 2002: Insect Clocks. Elsevier, Amsterdam, 560 pp.

Seko T., Miyatake T. \& Miura K. 2012: Assessment of hybrid vigor between flightless lines to restore survival and reproductive characteristics in the ladybird beetle Harmonia axyridis. — BioControl 57: 85-93.
Sloggett J.J. 2012: Harmonia axyridis invasions: Deducing evolutionary causes and consequences. - Entomol. Sci. 15: 261-273.

SlogGetT J.J. \& HoNĚK A. 2012: Genetic studies. In Hodek I., van Emden H.F. \& Honěk A. (eds): Ecology and Behaviour of the Ladybird Beetles (Coccinellidae). Wiley-Blackwell, Chichester, pp. 13-53.

SöDERLIND L. \& NYLIN S. 2011: Genetics of diapause in the comma butterfly Polygonia c-album. - Physiol. Entomol. 36: 8-13.

SuwA A. \& Gотон T. 2006: Geographic variation in diapause induction and mode of diapause inheritance in Tetranychus pueraricola. - J. Appl. Entomol. 130: 329-335.

TAKafuJ A. \& GoKA K. 1999: Mode of diapause inheritance in the Kanzawa spider mite, Tetranychus kanzawai (Acari: Tetranychidae). - Appl. Entomol. Zool. 34: 299-302.

TANAKA K. \& Murata K. 2016: Genetic basis underlying rapid evolution of an introduced insect Ophraella communa (Coleoptera: Chrysomelidae): Heritability of photoperiodic response. - Environ. Entomol. 46: 167-173.

Tauber M. J., Tauber C.A. \& Masaki S. 1986: Seasonal Adaptations of Insects. Oxford University Press, New York, 411 pp.

Turgeon J., Tayeh A., Facon B., Lombaert E., De Clerce P., Berkvens N., Lundgren J.G. \& Estoup A. 2011: Experimental evidence for the phenotypic impact of admixture between wild and biocontrol Asian ladybird (Harmonia axyridis) involved in the European invasion. - J. Evol. Biol. 24: 1044-1052.

Ukrainsky A.S. \& Orlova-BienKowskaja M.J. 2014: Expansion of Harmonia axyridis Pallas (Coleoptera: Coccinellidae) to European Russia and adjacent regions. - Biol. Invas. 16: 1003-1008.

Williams K.D., Busto M., Suster M.L., So A.K.C., Ben-Shahar Y., LeEVERS S.J. \& SoKolowski M.B. 2006: Natural variation in Drosophila melanogaster diapause due to the insulin-regulated PI3-kinase. - Proc. Natn. Acad. Sci. USA 103: 15911-15915.

XIA Q.W., Chen C., Tu X.Y., Yang H.Z. \& Xue F.S. 2012: Inheritance of photoperiodic induction of larval diapause in the Asian corn borer Ostrinia furnacalis. - Physiol. Entomol. 37: 185-191.

Xiao L., He H.M., Zhong P.S., Fu S., Chen C. \& Xue F.S. 2015: Inheritance of photoperiodic control of larval diapause in the Asian corn borer Ostrinia furnacalis (Guenée). - Bull. Entomol. Res. 105: 326-334.

Received July 20, 2017; revised and accepted October 3, 2017 Published online October 20, 2017 